\title{
Assessing progression of keratoconus: novel tomographic determinants
}

\author{
Joshua K. Duncan ${ }^{1}$, Michael W. Belin ${ }^{1 *}$ and Mark Borgstrom²
}

\begin{abstract}
Several methods have been described in the literature to both evaluate and document progression in keratoconus, but there is no consistent or clear definition of ectasia progression. The authors describe how modern corneal tomography, including both anterior and posterior elevation and pachymetric data can be used to screen for ectatic progression, and how software programs such as the Enhanced Reference Surface and the Belin-Ambrosio Enhanced Ectasia Display (BAD) can be employed to detect earlier changes. Additionally, in order to describe specific quantitative values that can be used as progression determinants, the normal noise measurement of the three parameters (corneal thickness at the thinnest point, anterior and posterior radius of curvature (ARC, PRC) taken from the $3.0 \mathrm{~mm}$ optical zone centered on the thinnest point), was assessed. These values were obtained by imaging five normal patients using three different technicians on three separate days. The $95 \%$ and $80 \%$ one-sided confidence intervals for all three parameters were surprisingly small (7.88/4.03 $\mu \mathrm{m}$ for corneal thickness, $0.024 / 0.012 \mathrm{~mm}$ for ARC, and 0.083/0.042 $\mathrm{mm}$ for PRC), suggesting that they may perform well as progression determinants.
\end{abstract}

Keywords: Keratoconus, Tomography, Ectatic disease, Progression, Amsler-Krumeich, Scheimpflug, Collagen cross-linking

\section{Background}

Keratoconus was first described in detail in 1854 as a chronic, non-inflammatory ectasia of the cornea. It is the most common primary ectasia, and is characterized by corneal steepening, visual distortion, apical corneal thinning, and central corneal scarring [1-3]. Corneal thinning typically occurs inferotemporal as well as central, although superior thinning has also been described [4]. Keratoconus usually becomes apparent during the second decade of the life, normally during puberty, and typically progresses until the fourth decade of life, when it usually stabilizes. The corneal thinning induces irregular astigmatism, myopia, and conical protrusion, leading to mild to marked impairment in the quality of vision, and often has a significant impact on patient's quality of life [1]. Keratoconus is relatively uncommon with a reported annual incidence of 2 per 100,000 and prevalence of 54.5 per 100,000 , though rates vary greatly in different geographic regions [5-7]. Keratoconus typically affects both eyes, although only one

\footnotetext{
* Correspondence: mwbelin@aol.com

${ }^{1}$ Department of Ophthalmology \& Vision Science, University of Arizona,

Tucson, AZ, USA

Full list of author information is available at the end of the article
}

eye may be affected initially $[8,9]$. The disease may be highly asymmetric $[8,9]$ and ocular symptoms and signs of keratoconus vary depending on disease severity. Early in the disease, and in subclinical keratoconus, there may be minimal or no symptoms, whereas in advanced disease there is significant distortion of vision accompanied by profound visual loss [10].

Several classification systems for keratoconus have been proposed in the literature [11-19]. The Amsler-Krumeich (AK) system is amongst the oldest and still the most widely used. In the AK system, the severity of keratoconus is graded from stage 1-4 using spectacle refraction, central keratometry, presence or absence of scarring, and central corneal thickness [20]. Others have used this system with various modification and additions in an attempt to better diagnosis or characterize the severity of disease [21, 22].

\section{Review \\ Documenting ectatic progression}

In addition to the various classification and grading systems described in the literature, having a standardized method to document ectatic progression is equally, if not more, important. The clinical decision to recommend treatments such as corneal crosslinking is based 
Table 1 Previously suggested parameters used to determine progression of ectatic disease

\begin{tabular}{|c|c|c|}
\hline Suggested Parameter & $\begin{array}{l}\text { Value Representing } \\
\text { Progression }\end{array}$ & Validated \\
\hline $\begin{array}{l}\text { Spherical power, and higher } \\
\text { order irregular astigmatism } \\
{[32,35]}\end{array}$ & $\begin{array}{l}\text { Positive Rate of } \\
\text { Change per Year }\end{array}$ & No \\
\hline $\begin{array}{l}\text { Spherical component, regular } \\
\text { astigmatism, decentration } \\
\text { component, and higher order } \\
\text { irregularity [37] }\end{array}$ & $\begin{array}{l}\text { Positive Rate of } \\
\text { Change per Year }\end{array}$ & No \\
\hline Kmax (steepest K) $[27,38]$ & $\geq 1.00 \mathrm{D}$ increase & No \\
\hline Kmax - Kmin [38] & $\geq 1.00 \mathrm{D}$ increase & No \\
\hline $\begin{array}{l}\text { Kmean (average of Kmax } \\
\text { and Kmin) }\end{array}$ & $\geq 0.75 \mathrm{D}$ increase & No \\
\hline Pachymetry [38] & $\begin{array}{l}\geq 2 \% \text { decrease in } \\
\text { central thickness }\end{array}$ & No \\
\hline $\begin{array}{l}\text { Back optic zone radius of the } \\
\text { best fitting contact lens [27] }\end{array}$ & $0.1 \mathrm{~mm}$ or more decrease & No \\
\hline $\begin{array}{l}\text { Increase in the central } \mathrm{K} \\
\text { power [25] }\end{array}$ & $\begin{array}{l}\geq 1.50 \mathrm{D} \text { increase } \\
\text { from baseline }\end{array}$ & No \\
\hline Manifest cylinder [38] & $\begin{array}{l}\text { Increase of } \geq 1.00 \mathrm{D} \\
\text { in } 24 \text { months }\end{array}$ & No \\
\hline $\begin{array}{l}\text { Manifest refraction spherical } \\
\text { equivalent change (MRSE) } \\
{[27,38]}\end{array}$ & $\geq 0.50 \mathrm{D}$ & No \\
\hline ISV [22] & $\begin{array}{l}\text { Specific values for } \\
\text { each KCN stage }\end{array}$ & No \\
\hline IHA [22] & $\begin{array}{l}\text { Specific values for } \\
\text { each KCN stage }\end{array}$ & No \\
\hline
\end{tabular}

largely on documented progressive ectasia. According to Global Consensus on Keratoconus and Ectatic Diseases (2015), there is no consistent or clear definition of ectasia progression [23]. This panel defined progression by a consistent change in at least two of the following parameters: steepening of the anterior corneal surface, steepening of the posterior corneal surface, and thinning and/or thinning or changes in the pachymetric rate of change, nevertheless the panel also agreed that specific quantitative data to define progression is lacking [23].

Several methods have been described in the literature to both evaluate and document progression in keratoconus. Early and more recent systems utilized serial topographic analysis alone to attempt to document disease progression $[24,25]$, whereas a number of newly proposed systems use complex keratometric indices to describe progression $[22,26]$.

Kmax (maximum anterior sagittal curvature) is the most commonly used parameter to detect or document ectatic progression and is regularly used as an indicator for crosslinking's efficacy [27-29]. Epstein et al. recommend the use of Kmax as a good single criterion to diagnose progression of keratoconus [30]. Kmax, however, has been acknowledged as a poor parameter for both progression and crosslinking efficacy [31-35]. Kmax represents the steepest anterior corneal curvature taken from a small area [30]. Kmax fails to reflect the degree of ectasia, ignores the contribution of the posterior cornea to progression and marked ectatic progression

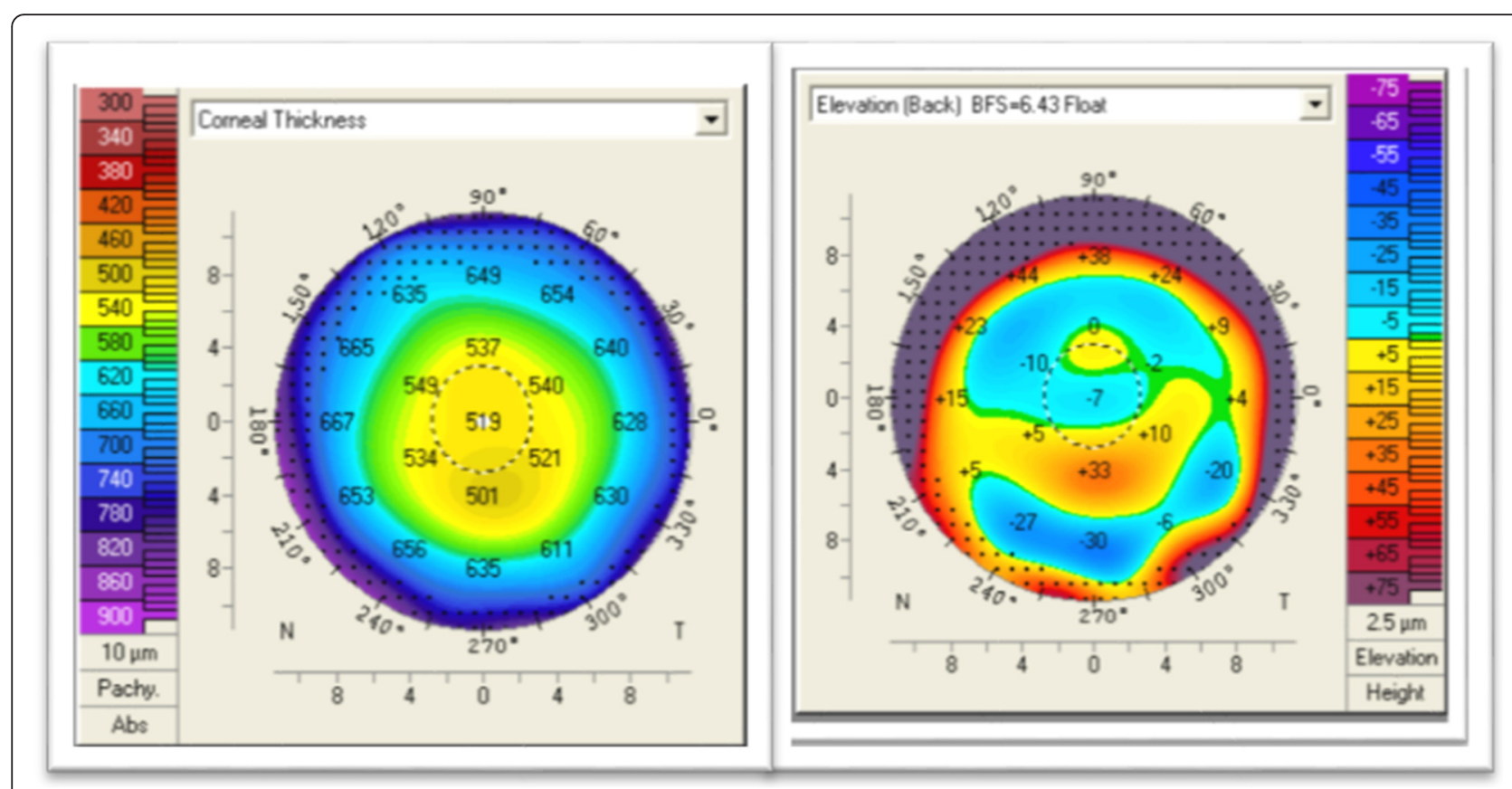

Fig. 1 Corneal thickness map (left) and Posterior elevation (right). The corneal thickness map shows a thinnest point that is displaced inferiorly and the posterior elevation reveals a prominent posterior island in an eye that has a normal anterior surface (Oculus Pentacam) 
can occur with no change or even a reduction in Kmax [32-34].

Kanellopoulos et al. looked at seven anterior surface Pentacam-derived topometric indices, concluding that the index of surface variance (ISV) and the index of height decentration (IHD) may be the most sensitive and specific criteria in the diagnosis and progression of keratoconus [22]. Others have looked at visual acuity, manifest refraction, and central corneal thickness as measures to follow ectatic progression, but these have also been found to be unreliable, and do not correlate well with severity of keratoconus [35-37]. A number of other parameters or systems have been advocated to document progression $[22,25,26,34-40]$. These include; observing for change on the posterior elevation maps, change in best corrected distance visual acuity, reduction in apical corneal thickness, or an increase in anterior corneal asymmetry. However, to the best of our knowledge, none of these have been validated in peerreviewed literature as methods to monitor progression. Additionally, these methods suffer from either being limited only to the anterior cornea or representing a small portion of the cornea, which may not properly depict changes in the ectatic region. Visual acuity methods are very variable, as many practitioners have seen how unpredictable these subjective measurements can be in a keratoconic patient [36]. Corneal thickness measurements are typically altered (thinned) after crosslinking, thus limiting its value to document progression as well [41] (Table 1).

It has been suggested that tomographic-derived pachymetry may be a more valuable method to document ectatic disease and follow progression [42]. Furthermore, changes in posterior corneal curvature [34], and corneal asymmetry have been shown to be additional methods of detecting early disease progression [22, 43, 44] (Fig. 1).

Other imaging techniques using Fourier series harmonic videokeratography and Fourier-Domain Optical Coherence Tomography (OCT) have been used to evaluate progression of keratoconus. Specifically, Oshika et al. looked at spherical power, regular astigmatism, decentration, and higher order irregular astigmatism as a means of quantifying advancement of ectasia [39]. OCT has been extensively utilized to evaluate total epithelial thickness, epithelial asymmetry, and biomechanical factors, which may be used to document progression of keratoconus [19]. The multitude of suggested progression parameters speaks to the need for a new or standardized method to document progression [23].

\section{Tomographic-based assessment of ectatic progression}

Modern corneal tomography (as opposed to topography) allows for the measurement of the anterior and posterior corneal surfaces as well as the anterior lens (Fig. 2) [45].

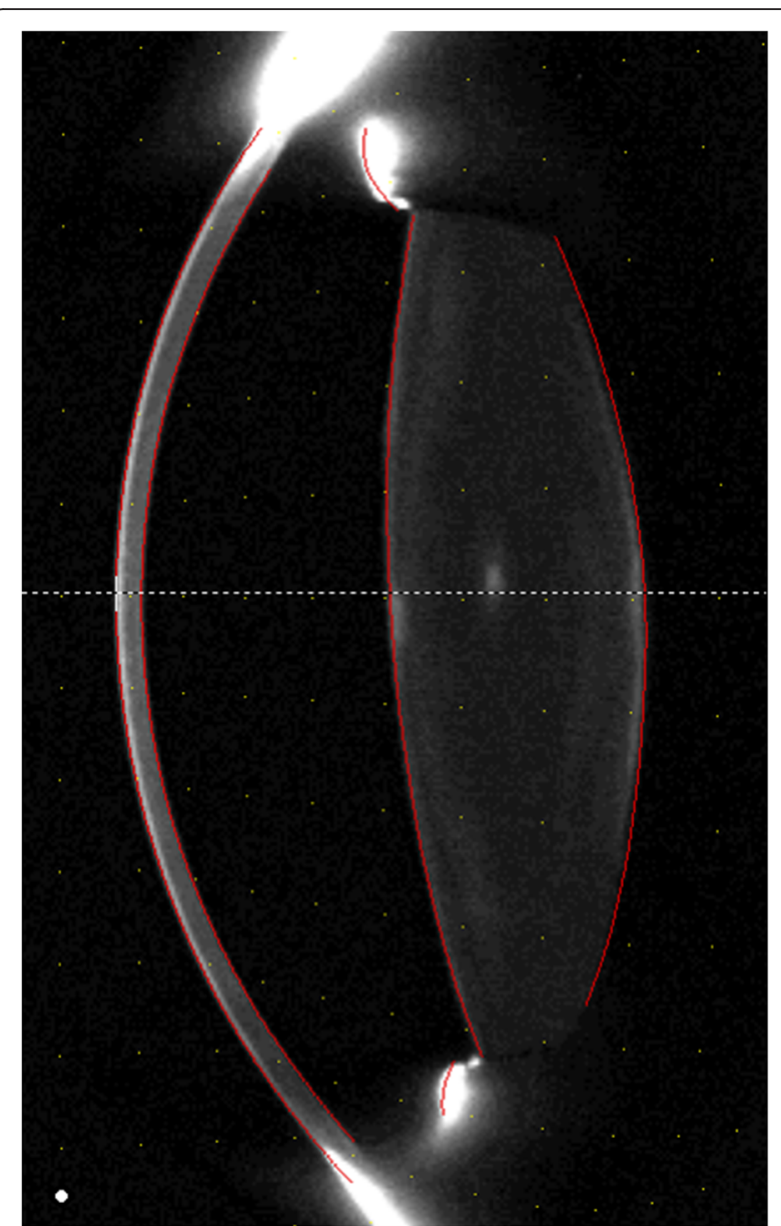

Fig. 2 Scheimpflug optical cross section with edge detection turned on, showing the anterior corneal surface, posterior corneal surface, anterior and posterior lens surfaces identified (Oculus Pentacam)

With this information, both corneal thickness and anterior chamber depth can be computed. Early ectatic change is typically seen on the posterior corneal surface prior to anterior changes (Fig. 1) [33]. Additionally, alterations in the corneal thickness, such as a more rapid change from the thinnest point to the periphery can be seen in early keratoconus even with normal anterior and posterior elevation maps (Fig. 3) [42].

The additional information available from anterior segment tomographic devices has led to the development of various refractive surgery screening programs. $[14,42,46-48]$. One such program is the BelinAmbrosio Enhanced Ectrasia Display (BAD). The BAD display (available on the Pentacam, OCULUS GmbH, Wetzlar, Germany) utilizes both anterior and posterior elevation data and pachymetric data to screen for ectatic change $[49,50]$. It displays the elevation data against the commonly used best-fit-sphere (BFS) taken from the central $8.0 \mathrm{~mm}$ zone, but also uses a newly developed reference surface called the "Enhanced Reference Surface." 


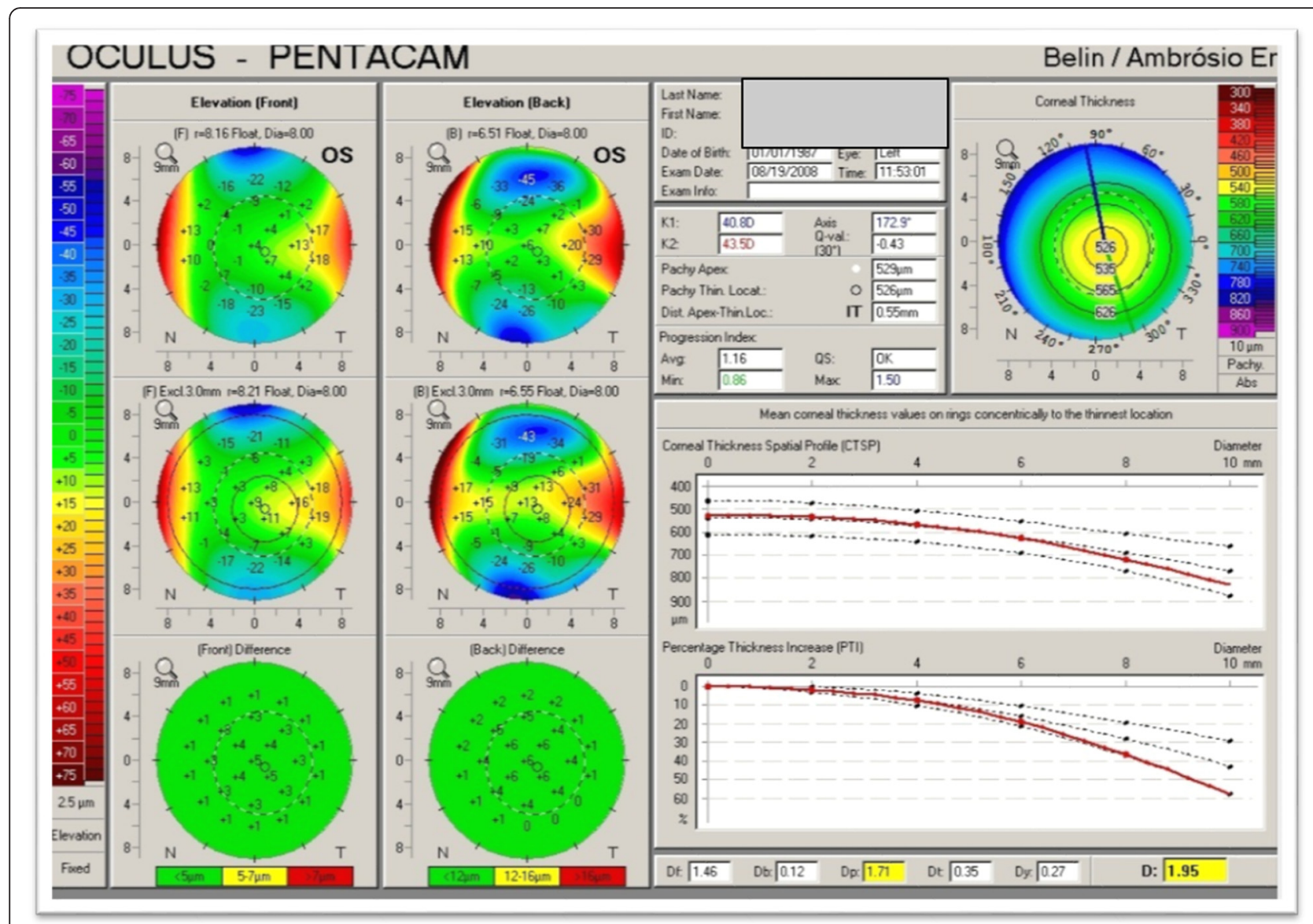

Fig. 3 Contralateral eye in a patient with advanced keratoconus in the other eye. The only abnormality seen here (BAD display) is a mild abnormality in the pachymetric progression (Oculus Pentacam)

While the Best-Fit-Sphere (BFS) is both quantitatively and qualitatively useful, the clinician typically assumes that the reference surface closely approximates a "normal" cornea. This is actually not the case for ectatic corneas where the reference surface (typically a BFS taken from the central $8 \mathrm{~mm}$ zone) incorporates all data from the specified zone including normal and abnormal cornea [51]. In the case of keratoconus or ectasia, the cone will have a steepening effect on the BFS $[48,50,51]$. This steepened BFS will minimize the elevation difference between the apex of the cone and the BFS.

The concept behind the "Enhanced Reference Surface" is to generate a reference surface that more closely resembles the patient's own normal portion of the cornea as this will further magnify any existing pathology. To generate this new reference surface, a smaller diameter optical zone (exclusion zone) centered on the thinnest portion of the cornea is excluded from the $8.0 \mathrm{~mm}$ optical zone used for the standard BFS computation. The "enhanced BFS" is generated by utilizing all the valid elevation data from within the $8.0 \mathrm{~mm}$ central cornea, and outside the exclusion zone (Fig. 4).
The exact size of the exclusion zone varies between 3.0 to $4.0 \mathrm{~mm}$ based on a proprietary algorithm, but is typically $3.0 \mathrm{~mm}$ for keratoconic corneas. The resulting new reference surface ("Enhanced Reference Surface) more closely approximates the more normal peripheral cornea and exaggerates any conical protrusion (Fig. 5).

The enhanced reference surface was not only qualitatively useful in visualizing subtle or early ectatic change, but the elevation difference between a standard BFS and the enhanced reference surface also proved to be highly significant quantitatively in separating normal eyes from those with ectatic change [50].

The choice of the exclusion zone centered on the thinnest point was multifactorial. The size of the exclusion zone had to be large enough to have more global representation than single parameters such as Kmax, but if the area was too large, then more "normal" cornea would be included; for displaced cones, far peripheral or extrapolated data would be incorporated. Extensive comparative testing resulted in the selection of a variable 3.0 to $4.0 \mathrm{~mm}$ exclusion zone $[50,51]$. The enhanced reference surface works because the exclusion zone centered on the thinnest point 


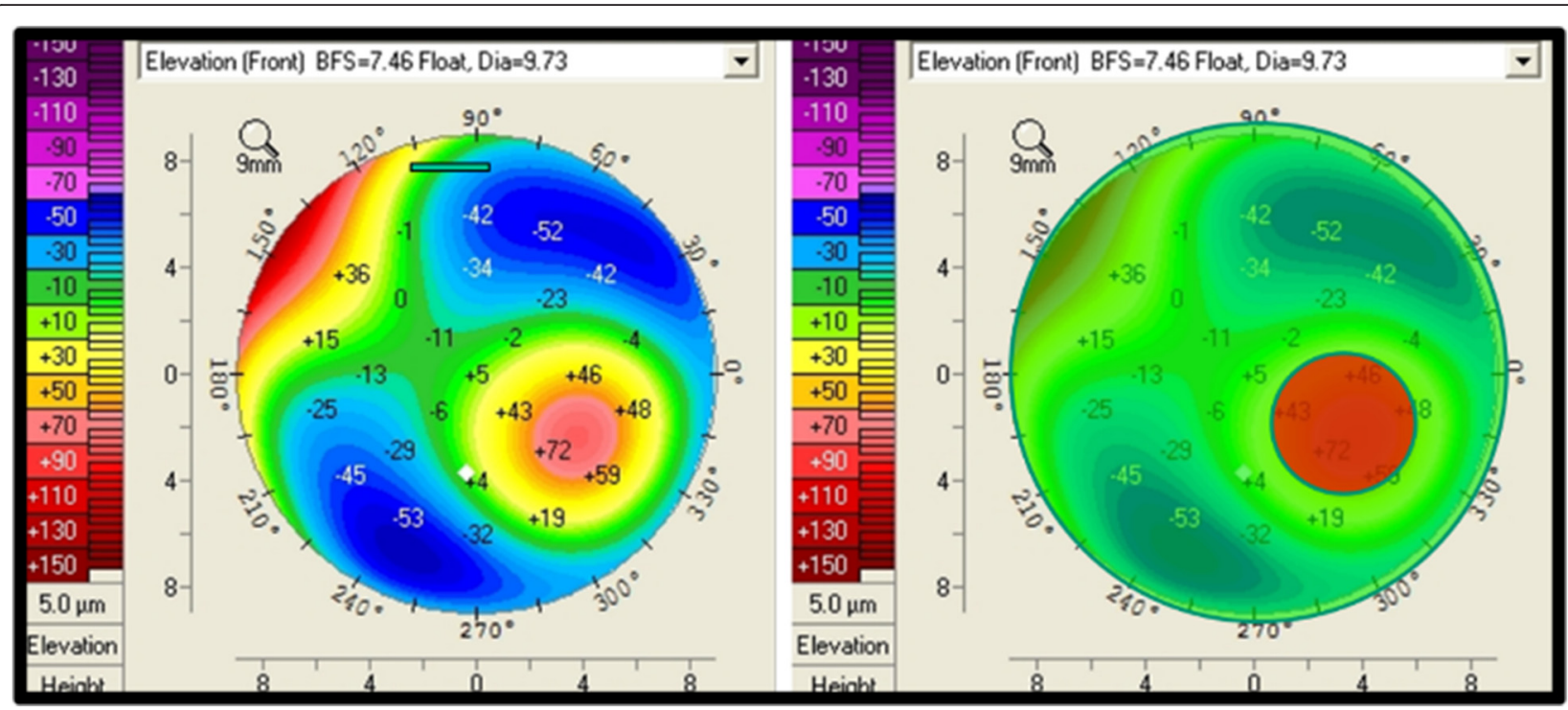

Fig. 4 Anterior elevation map (left) showing a prominent paracentral positive island indicative of keratoconus. The map of the left highlights in red the $3.0 \mathrm{~mm}$ exclusion zone centered on the thinnest point that is removed from the calculation of the enhanced reference surface

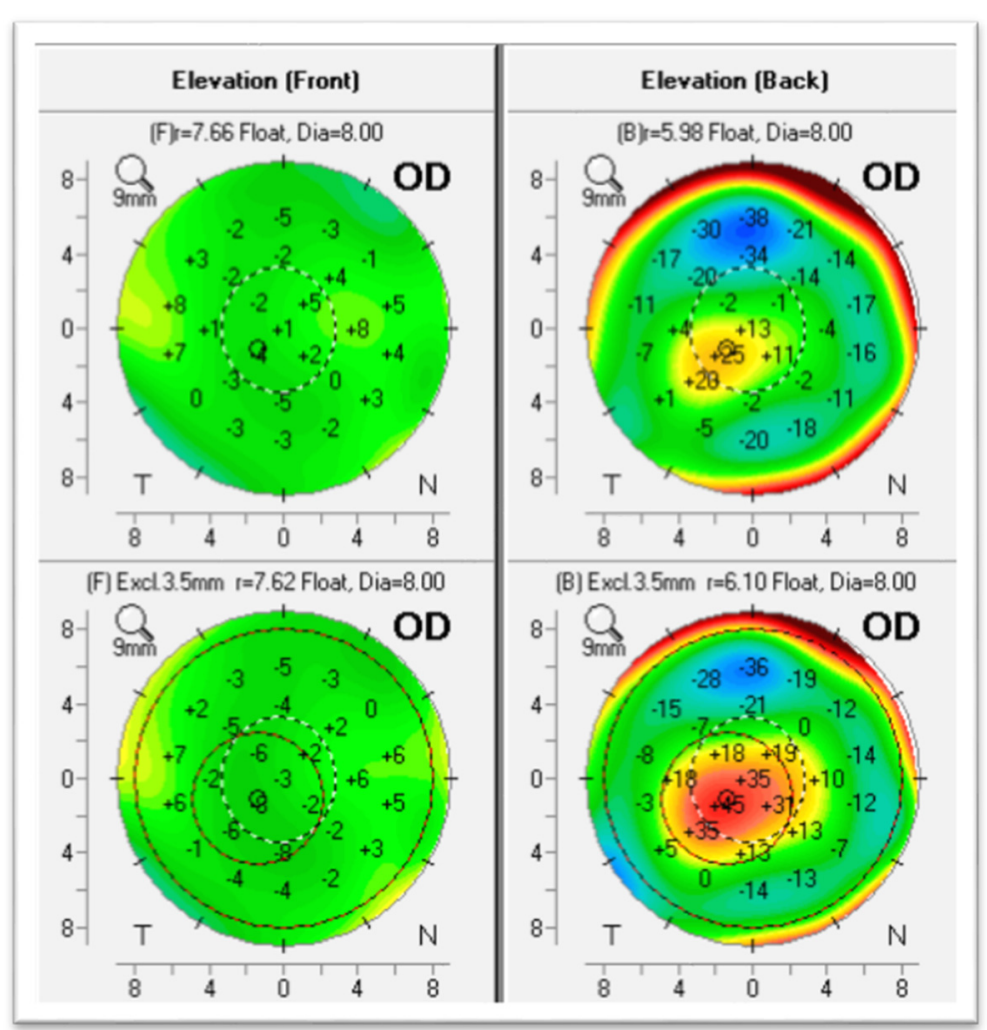

Fig. 5 Anterior and Posterior elevation maps with the standard BFS (upper maps) and "enhanced reference surface" (lower maps). The standard anterior map (upper left) shows minimal changes against the enhanced reference surface (lower left) as the anterior surface is normal. The standard posterior elevation (upper right) shows an early positive island of elevation that is exaggerated using the enhanced reference surface (lower right) (Oculus Pentacam) 
incorporates the major ectatic region. Excluding this zone from the standard $8 \mathrm{~mm}$ BFS results in a reference surface that closely mimics the more normal portions of the cornea.

A similar concept has been used in a new keratoconus grading system $[52,53]$. As opposed to excluding the 3.0 to $4.0 \mathrm{~mm}$ zone to normalize the reference surface, we employed the exclusion zone centered on the thinnest point as this area more globally represents the ectatic region than a single point parameter such as Kmax or maximal elevation. The newly described $\mathrm{ABCD}$ keratoconus grading system uses the anterior and posterior radius of curvature taken from the $3 \mathrm{~mm}$ zone centered on the thinnest point ("A" for anterior, "B" for back surface) and the corneal thickness at the thinnest point ("C $\mathrm{C}$ " for corneal thickness) as well as best corrected distance visual acuity ("D" for distance visual acuity). This new classification/ grading system has advantages over the older AmslerKrumeich classification in that it recognizes the importance of the posterior corneal surface and each component (anterior, posterior, thickness, visual acuity) are individually graded. The "Belin ABCD" grading system has been incorporated in the OCULUS Pentacam software version $6.08 \mathrm{r} 16$ as part of the Topometric/Keratoconus Grading Display (Fig. 6).

Similarly, the determination of progression, or the lack of, is paramount to determine when and if to treat and to document treatment efficacy. As with the older grading systems, the problem with many of the commonly used progression parameters is that they were either limited to the anterior corneal surface (Kmax), or were measured on the corneal apex (Kmax, apical pachymetry) which often does not adequately reflect the cone. Changes in the cone may occur with little or any changes in the apical cornea. This would be particularly true for decentered cones. Additionally, changes on the posterior cornea may occur without concurrent anterior changes and they may be posterior progression in spite of a normal anterior surface (subclinical keratoconus) (Fig. 7). Progressive posterior ectasia will be accompanied by further corneal thinning, but this may not be detected only by taking measurements at the corneal apex.

Measuring corneal thickness change at the thinnest point should be a more sensitive indicator of progression than apical pachymetry. Changes to the anterior and posterior BFS taken from the $3.0 \mathrm{~mm}$ zone centered on the thinnest point should also be a more sensitive indicator of cone progression. The $3.0 \mathrm{~mm}$ zone was selected for the same reasons it was used in the $A B C D$ grading system as this is the exclusion zone the BAD software chooses for most ectatic corneas. Because all three parameters are centered on the thinnest point (surrogate for center of the cone) and limited to the conical region, they should reflect change earlier than more global parameters (e.g. IHD,

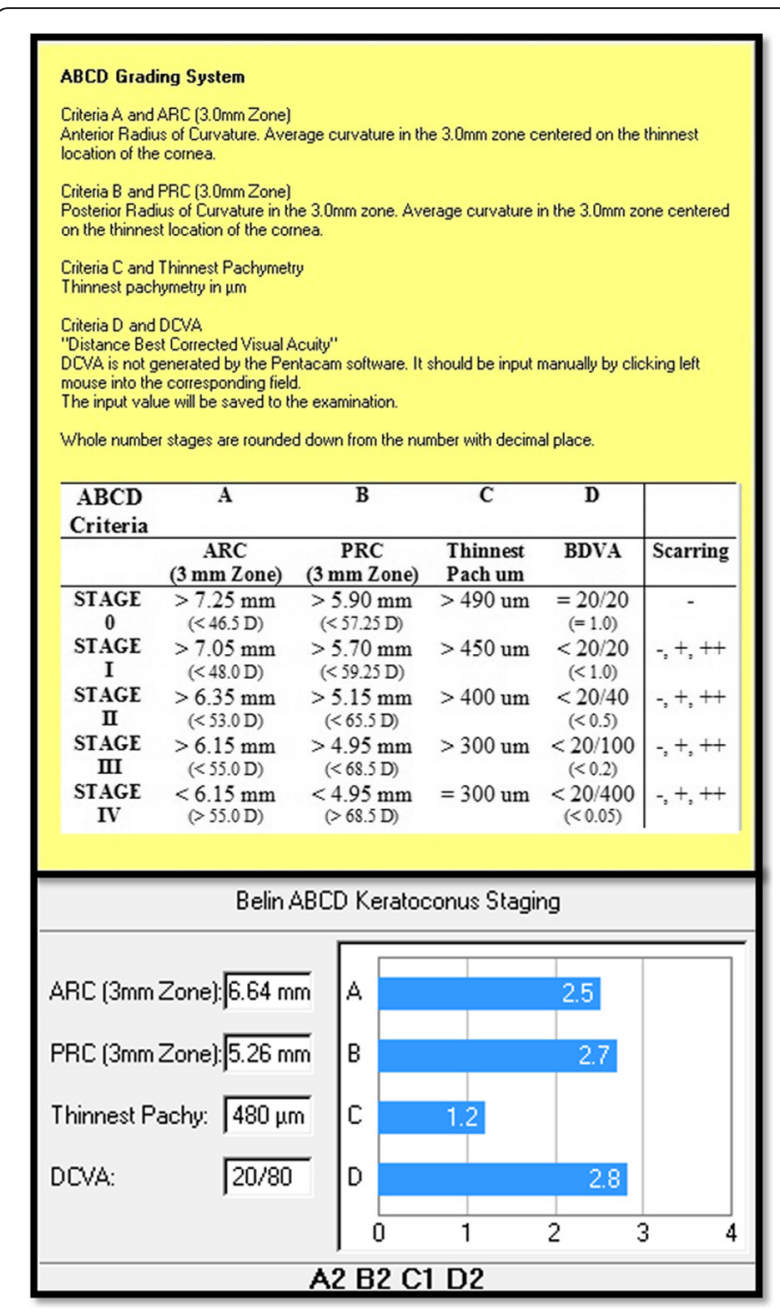

Fig. 6 The ABCD Keratoconus Grading system currently available on the Topometric/Keratoconus Grading display on the OCULUS Pentacam

ISV) and/or parameters measured from the corneal apex. In order to utilize these parameters as indicators of progression, the normal measurement noise needs to be known. This allows us to separate measurement variance from true change. While numerous articles have been written on normal values generated by Scheimpflug imaging or OCT $[48,49,54,55]$, there are no available data on anterior and posterior curvature from the $3.0 \mathrm{~mm}$ zone centered on the thinnest point as these parameters have not been previously described.

To determine the measurement noise of the three parameters (corneal thickness at the thinnest point, and anterior and posterior radius of curvature (ARC, PRC) taken from the $3.0 \mathrm{~mm}$ optical zone centered on the thinnest point), five volunteer subjects were imaged, after obtaining informed consent, by three different technicians on three different days separated by 2 weeks (Pentacam HR, software version 6.08r13). Each technician imaged each patient three times for each 


\section{OCULUS - PENTACAM Belin / Ambrósio Enhanced Ectasia}

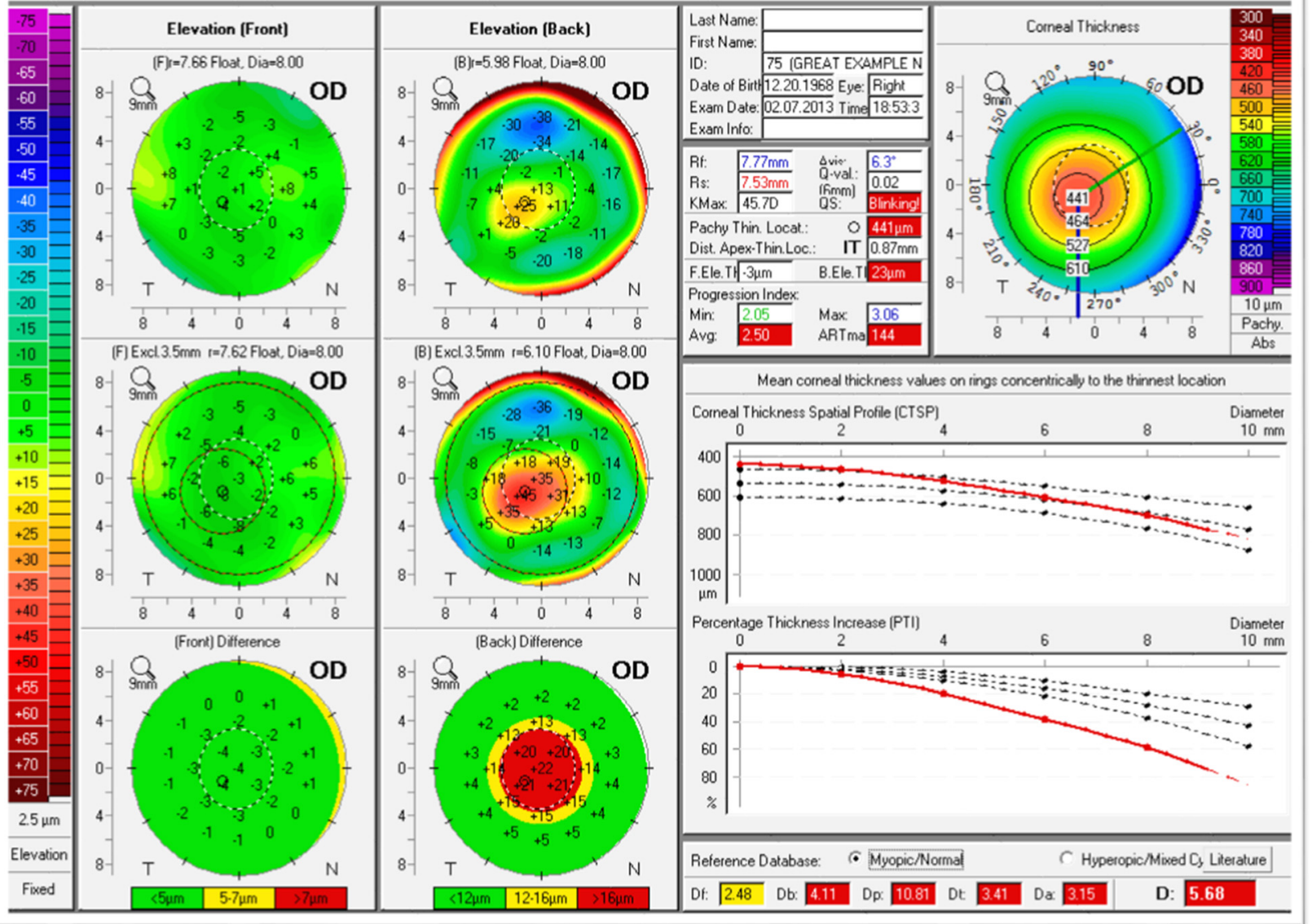

Fig. 7 An example of subclinical keratoconus. The cornea is substantially thinned with a prominent posterior ectasia in spite of a normal anterior surface (BAD display, Oculus Pentacam)

time period for a total of 27 images per patient, 135 images total. Patients were removed from the instrument after each image. Each technician was instructed to acquire three images with an acceptable quality check (machine verification of an acceptable image). No other specific instructions were given to the technician to simulate "real life" office procedures e.g., variation in time of day. Specially designed software was used to extract ARC, PRC, and thinnest pachymetry (Table 2). The study protocol was approved by the University of Arizona (Tucson, Arizona) Institutional Review Board.

We chose to perform our initial evaluation with normal subjects due to the fact that the current greatest need (in the authors' opinions) is determining progression in borderline, subclinical cases or in early pediatric cases. Here, the normal patient variation is probably more applicable and more closely approximates very early disease than values determined from known cases of keratoconus. There are many surgeons who promote crosslinking in children at the first sign of ectatic change. Here, using parameters deduced from keratoconus patients would probably delay treatment. Additionally, while using cases of subclinical keratoconus would be germane, there still is no universal agreement on what constitutes subclinical disease, with many investigators still utilizing Amsler-Krumeich and relying on anterior surface topography [10, 23]. Future work, however, will evaluate patients with mild to moderate disease.

Table 2 Mean and Standard Deviation of each of the five subjects for thinnest pachymetry, ARC, and PRC

\begin{tabular}{lccc}
\hline Patient & Minimal Pach $(\mu \mathrm{m})$ & $\begin{array}{l}\text { ARC from } 3.0 \mathrm{~mm} \\
\text { zone }(\mathrm{mm})\end{array}$ & $\begin{array}{l}\text { PRC from } 3.0 \mathrm{~mm} \\
\text { zone }(\mathrm{mm})\end{array}$ \\
\hline 1 & $513.93 \pm 6.49$ & $7.35 \pm 0.017$ & $5.91 \pm 0.033$ \\
2 & $521.81 \pm 4.47$ & $7.83 \pm 0.016$ & $6.40 \pm 0.079$ \\
3 & $519.85 \pm 3.02$ & $7.43 \pm 0.008$ & $5.98 \pm 0.033$ \\
4 & $491.37 \pm 5.06$ & $7.59 \pm 0.011$ & $6.21 \pm 0.060$ \\
5 & $563.37 \pm 4.23$ & $7.83 \pm 0.017$ & $6.49 \pm 0.027$ \\
\hline
\end{tabular}

$A R C=$ anterior radius of curvature, $P R C=$ posterior radius of curvature 
Table 3 Standard deviation and $80 \%$ and $95 \%$ one-sided confidence intervals for corneal thickness, ARC and PRC for the pooled data

\begin{tabular}{lccc}
\hline & $\begin{array}{c}\text { Minimal } \\
\text { Pach }(\mu \mathrm{m})\end{array}$ & $\begin{array}{c}\text { ARC from } 3.0 \mathrm{~mm} \\
\text { zone }(\mathrm{mm})\end{array}$ & $\begin{array}{l}\text { PRC from } 3.0 \mathrm{~mm} \\
\text { zone }(\mathrm{mm})\end{array}$ \\
\hline Standard Dev & 4.79 & 0.015 & 0.050 \\
$95 \%$ one-tailed $\mathrm{Cl}$ & 7.88 & 0.024 & 0.083 \\
$80 \%$ one-tailed $\mathrm{Cl}$ & 4.03 & 0.012 & 0.042 \\
\hline
\end{tabular}

$A R C=$ anterior radius of curvature, $P R C=$ posterior radius of curvature, $\mathrm{Cl}=$ confidence interval

In order to determine the suitability of the above three parameters as potential progression determinants, both a pooled variance estimate and a one-sided confidence interval were computed using both SPSS version 23 (IBM Corp., Armonk, NY) and STATA 13 (StataCorp LP, College Station, TX). A one-sided confidence interval was chosen because progression is indicated by thinning and/or steepening of the anterior and/or posterior corneal surfaces. For each of these parameters (corneal thickness, ARC, PRC) a decrease would be indicative of progression. Both $95 \%$ and $80 \%$ confidence intervals were determined since the risk/benefit ratio for medical/ surgical intervention would vary based on the age of the patient, family history, condition of the other eye, etc., (Table 3) and both the physician and patient's decisions would differ greatly based on a multitude of factors.

\section{Conclusion}

As earlier noted, according to Global Consensus on Keratoconus and Ectatic Diseases (2015), there is no consistent or clear definition of ectasia progression [23]. The panel defined progression by a consistent change in at least two of the following parameters: steepening of the anterior corneal surface, steepening of the posterior corneal surface, and thinning and/or thinning or changes in the pachymetric rate of change. The panel, however, acknowledged that specific quantitative data to define progression is lacking [23]. Our goal was to determine the quantitative values and to access their suitability as progression determinants. Both the $95 \%$ and $80 \%$ one-sided confidence intervals for all three parameters were surprisingly small $(7.88 /$ $4.03 \mu \mathrm{m}$ for corneal thickness, $0.024 / 0.012 \mathrm{~mm}$ for ARC, and $0.083 / 0.042 \mathrm{~mm}$ for PRC) suggesting that they may perform well as progression determinants. The limitation of the study is that the confidence intervals were determined on normal subjects and it is highly likely that measurement variability would be greater in ectatic corneas, though these values probably reflect early disease fairly well. The use of normal subjects was based on practical reasons since it would be difficult to have patients return on multiple days for measurements, though this is something we will pursue in the future. Finally, while minimal corneal thickness is readily available on all tomographic systems, ARC and PRC taken from the $3 \mathrm{~mm}$ zone centered on the thinnest point is a new parameter and currently only available on the OCULUS Pentacam, but would be simple to incorporate in any tomographic imaging system. The use of these parameters in addition to the $\mathrm{ABCD}$ grading system should offer an improved method of classifying and grading keratoconus and assist in documenting progression of disease.

\section{Competing interests}

The authors declare that they have no competing interests. Michael W Belin is a consultant to OCULUS GmbH. He receives no funds for software development or sales. The remaining authors have no competing interests.

\section{Authors' contributions}

JD \& MWB performed the patient examinations, literature review and drafted the manuscript. MB performed the statistical analysis. All authors read and approved the final manuscript.

\section{Author details}

${ }^{1}$ Department of Ophthalmology \& Vision Science, University of Arizona, Tucson, AZ, USA. ${ }^{2}$ University of Arizona, University Information Technology Services, Tucson, AZ, USA.

Received: 22 October 2015 Accepted: 22 February 2016

Published online: 11 March 2016

\section{References}

1. Nottingham J. Practical Observations on Conical Cornea: and on the Short Sight, and Other Defects of Vision Connected with it. London: J Churchill; 1854.

2. Rabinowitz YS. Keratoconus. Surv Ophthalmol. 1998:42:297-319.

3. Krachmer JH, Feder RS, Belin MW. Keratoconus and related non- inflammatory corneal thinning disorders. Surv Ophthalmol. 1984;28:293-322.

4. Weed $\mathrm{KH}, \mathrm{McGhee} \mathrm{CN}$, Mac Ewen CJ. Atypical unilateral superior keratoconus in young males. Cont Lens Anterior Eye. 2005;28:177-9.

5. Gorskova EN, Sevost'ianov EN. Epidemiology of keratoconus in the Urals. Vestn Oftalmol. 1998;114:38-40.

6. Jonas JB, Nangia V, Matin A, Kulkarni M, Bhojwani K. Prevalence and associations of keratoconus in rural maharashtra in central India: the central India eye and medical study. Am J Ophthalmol. 2009;148:760-5.

7. Kennedy RH, Bourne WM, Dyer JA. A 48-year clinical and epidemiologic study of keratoconus. Am J Ophthalmol. 1986;101:267-73.

8. Lee LR, Hirst LW, Readshaw G. Clinical detection of unilateral keratoconus. Aust N Z J Ophthalmol. 1995;23:129-33.

9. Rabinowitz YS, Nesburn AB, McDonnell PJ. Videokeratography of the fellow eye in unilateral keratoconus. Ophthalmology. 1993;100:181-6.

10. Belin MW, Kim J, Zloty P, Ambrósio Jr R. Simplified nomenclature for describing keratoconus. J Kerat Ect Cor Dis. 2012;1(1):31-5.

11. Perry HD, Buxton JN, Fine BS. Round and oval cones in keratoconus. Ophthalmology. 1980;87:905-9.

12. Krumeich JH, Daniel J, Knülle A. Live-epikeratophakia for keratoconus. J Cataract Refract Surg. 1998;24:456-63.

13. Rabinowitz YS, Rasheed K. KISA \% index: a quantitative videokeratography algorithm embodying minimal topographic criteria for diagnosing keratoconus. J Cataract Refract Surg. 1999;25:1327-35.

14. Maeda N, Klyce SD, Smolek MK, Thompson HW. Automated keratoconus screening with corneal topography analysis. Invest Ophthalmol Vis Sci. 1994; 35:2749-57

15. Alió JL, Shabayek MH. Corneal higher order aberrations: a method to grade keratoconus. J Refract Surg. 2006;22:539-45.

16. McMahon TT, Szczotka-Flynn L, Barr JT, Anderson RJ, Slaughter ME, Lass JH, et al. A new method for grading the severity of keratoconus: the Keratoconus Severity Score (KSS). Cornea. 2006;25:794-800.

17. Mahmoud AM, Roberts CJ, Lembach RG, Twa MD, Herderick EE, McMahon TT. CLMI: the cone location and magnitude index. Cornea. 2008;27:480-7. 
18. Li X, Yang H, Rabinowitz YS. Keratoconus: classification scheme based on videokeratography and clinical signs. J Cataract Refract Surg. 2009;35:1597-603.

19. Sandali O, El Sanharawi M, Temstet C, Hamiche T, Galan A, Ghouali W, et al. Fourier-domain optical coherence tomography imaging in keratoconus: a corneal structural classification. Ophthalmology. 2013;120(12):2403-12.

20. Amsler M. Keratocone classique et keratocone fruste; arguments unitaires. Ophtalmologica. 1946;111:96-101

21. Kamiya K, Ishii R, Shimizu K, Igarashi A. Evaluation of corneal elevation, pachymetry and keratometry in keratoconic eyes with respect to the stage of Amsler-Krumeich classification. Br J Ophthalmol. 2014;98(4):459-63.

22. Kanellopoulos AJ, Asimellis G. Revisiting keratoconus diagnosis and progression classification based on evaluation of corneal asymmetry indices, derived from Scheimpflug imaging in keratoconic and suspect cases. Clin Ophthalmol. 2013;7:1539-48.

23. Gomes JA, Tan D, Rapuano CJ, Belin MW, Ambrósio Jr R, Guell JL, et al. Globa consensus on keratoconus and ectatic disease. Cornea. 2015;34:359-69.

24. Maguire $\sqcup$, Lowry JC. Identifying progression of subclinical keratoconus by serial topography analysis. Am J Ophthalmol. 1991;112:41-5.

25. Choi JA, Kim MS. Progression of keratoconus by longitudinal assessment with corneal topography. Invest Ophthalmol Vis Sci. 2012;53(2):927-35

26. Li X, Yang H, Rabinowitz YS. Longitudinal study of keratoconus progression. Exp Eye Res. 2007;85(4):502-7.

27. Wittig-silva C, Chan E, Islam FM, Wu T, Whiting M, Snibson GR. A randomized, controlled trial of corneal collagen cross-linking in progressive keratoconus: three-year results. Ophthalmology. 2014;121(4):812-21.

28. O'Brart DP, Chan E, Samaras K, Patel P, Shah SP. A randomized, prospective study to investigate the efficacy of riboflavin/ultraviolet $A(370 \mathrm{~nm})$ corneal collagen cross-linking to halt progression of keratoconus. Br J Ophthalmol. 2011:95:1519-24.

29. Sykakis E, Karim R, Evans JR, Bunce C, Amissah-Arthur KN, Patwary S, et al. Corneal collagen cross-linking for treating keratoconus. Cochrane Database Syst Rev. 2015;3:CD010621.

30. Epstein RL, Chiu YL, Epstein GL. Pentacam HR criteria for curvature change in keratoconus and postoperative LASIK ectasia. J Refract Surg. 2012;28(12): 890-4.

31. Barbara R, Castillo JH, Hanna R, Berkowitz E, Tiosano B, Barbara A. Keratoconus Expert Meeting, London, 2014. J Kerat Ect Cor Dis. 2014;3(3):141-58.

32. Mahmoud AM, Nuñez MX, Blanco C, Koch DD, Wang L, Weikert MP, et al. Expanding the cone location and magnitude index to include corneal thickness and posterior surface information for the detection of keratoconus. Am J Ophthalmol. 2013;156(6):1102-11.

33. De sanctis U, Loiacono C, Richiardi L, Turco D, Mutani B, Grignolo FM. Sensitivity and specificity of posterior corneal elevation measured by Pentacam in discriminating keratoconus/subclinical keratoconus. Ophthalmology. 2008;115(9):1534-9.

34. Tomidokoro A, Oshika T, Amano S, Higaki S, Maeda N, Miyata K. Changes in anterior and posterior corneal curvatures in keratoconus. Ophthalmology. 2000;107(7):1328-32

35. Lopes BT, Ramos IC, Faria-Correia F, Luz A, de Freitas Valbon B, Belin MW, et al. Correlation of topometric and tomographic indices with visual acuity in patients with keratoconus. J Kerat Ect Cor Dis. 2012;1(3):167-72.

36. Kanellopoulos AJ, Moustou V, Asimellis G. Evaluation of visual acuity, pachymetry and anterior-surface irregularity in keratoconus and crosslinking intervention follow-up in 737 cases. J Kerat Ect Cor Dis. 2013;2(3):95-103.

37. Suzuki M, Amano S, Honda N, Usui T, Yamagami S, Oshika T. Longitudinal changes in corneal irregular astigmatism and visual acuity in eyes with keratoconus. Jpn J Ophthalmol. 2007;51(4):265-9.

38. Chatzis N, Hafezi F. Progression of keratoconus and efficacy of pediatric corneal collagen cross-linking in children and adolescents. J Refract Surg. 2012;28(11):753-8.

39. Oshika T, Tanabe T, Tomidokoro A, Amano S. Progression of keratoconus assessed by fourier analysis of videokeratography data. Ophthalmology. 2002;109(2):339-42

40. Hersh PS, Greenstein SA, Fry KL. Corneal collagen crosslinking for keratoconus and corneal ectasia: One-year results. J Cataract Refract Surg. 2011;37(1):149-60.

41. Sefic kasumovic S, Racic-Sakovic A, Kasumovic A, Pavljasevic S, Duric-Colic B,

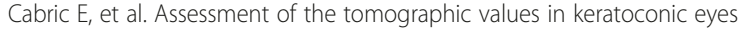
after collagen crosslinking procedure. Med Arch. 2015;69(2):91-4.
42. Ambrósio Jr R, Caiado AL, Guerra FP, Louzada R, Roy AS, Luz A. Novel pachymetric parameters based on corneal tomography for diagnosing keratoconus. J Refract Surg. 2011;27(10):753-8.

43. Kanellopoulos AJ, Asimellis G. OCT corneal epithelial topographic asymmetry as a sensitive diagnostic tool for early and advancing keratoconus. Clin Ophthalmol. 2014;8:2277-87.

44. Khachikian SS, Belin MW, Ciolino JB. Intrasubject corneal thickness asymmetry. J Refract Surg. 2008;24(6):606-9.

45. Koch DD, Ali SF, Weikert MP, Shirayama M, Jenkins R, Wang L. Contribution of posterior corneal astigmatism to total corneal astigmatism. J Cataract Refract Surg. 2012:38(12):2080-7.

46. Fam HB, Lim KL. Corneal elevation indices in normal and keratoconic eyes. J Cataract Refract Surg. 2006;32(8):1281-7.

47. Chastang PJ, Borderie VM, Carvajal-gonzalez S, Rostène W, Laroche L. Automated keratoconus detection using the EyeSys videokeratoscope. J Cataract Refract Surg. 2000;26(5):675-83.

48. Belin MW, Ambrósio R. Scheimpflug imaging for keratoconus and ectatic disease. Indian J Ophthalmol. 2013;61(8):401-6.

49. Orucoglu F, Toker E. Comparative analysis of anterior segment parameters in normal and keratoconus eyes generated by scheimpflug tomography. J Ophthalmol. 2015;2015:925414.

50. Belin MW, Khachikian SS, Ambrósio Jr R, Salomão M. Keratoconus/ectasia detection with the oculus pentacam: Belin/Ambrósio enhanced ectasia display. Highlights Ophthalmol. 2007;35:5-12.

51. Villavicencio OF, Gilani F, Henriquez MA, Izquierdo Jr L, Ambrósio Jr R, Belin MW. Independent population validation of the Belin/Ambrosio enhanced ectasia display: implications for keratoconus studies and screening. Int J Kerat Ect Cor Dis. 2014;3(1):1-8.

52. Belin MW, Duncan JK, Ambrósio Jr R, Gomes JAP. A new tomographic method of staging/classifying keratoconus: the ABCD grading system. Int J Kerat Ect Cor Dis. 2015:4(3):55-63.

53. Belin MW, Duncan JK. Keratoconus. The ABCD Grading System. Klin Monb Augenheilkd. 2016 Jan 20. [Epub ahead of print].

54. Feng MT, Belin MW, Ambrósio Jr R, Grewal SP, Yan W, Shaheen MS, et al. International values of corneal elevation in normal subjects by rotating Scheimpflug camera. J Cataract Refract Surg. 2011;37(10):1817-21.

55. Gilani F, Cortese M, Ambrósio Jr RR, Lopes B, Ramos I, Harvey EM, et al. Comprehensive anterior segment normal values generated by rotating Scheimpflug tomography. J Cataract Refract Surg. 2013;39(11):1707-12.

\section{Submit your next manuscript to BioMed Central and we will help you at every step:}

- We accept pre-submission inquiries

- Our selector tool helps you to find the most relevant journal

- We provide round the clock customer support

- Convenient online submission

- Thorough peer review

- Inclusion in PubMed and all major indexing services

- Maximum visibility for your research

Submit your manuscript at www.biomedcentral.com/submit

) Biomed Central 